\title{
PR-13/Thionin But Not PR-1 Mediates Bacterial Resistance in Nicotiana attenuata in Nature, and Neither Influences Herbivore Resistance
}

\author{
Cbgowda Rayapuram, Jianqiang Wu, Christiane Haas, and lan T. Baldwin \\ Department of Molecular Ecology, Max Planck Institute for Chemical Ecology, Hans-Knöll Str. 8, D-07745 Jena, Germany \\ Submitted 26 November 2007. Accepted 3 March 2008.
}

\begin{abstract}
Increases in pathogenesis-related $(P R)$ transcripts are commonly interpreted as evidence of plants' resistance responses to pathogens; however, few studies have examined whether increases in PR proteins protect plants growing under natural conditions. Pseudomonas syringae pv. tomato DC3000, which is virulent and causes disease in Arabidopsis, is also pathogenic to the native tobacco Nicotiana attenuata. $N$. attenuata responds to $P$. syringae pv. tomato DC3000's challenges with increases in salicylic acid and transcripts of at least two $P R$ genes, $P R-1$ and $P R 13 /$ Thionin. To determine if either of these $P R$ proteins functions in bacterial resistance, we independently silenced both genes by RNAi and found that only $P R-13 /$ Thionin mediates resistance to $P$. $s y$ ringae pv. tomato $\mathrm{DC} 3000$ in glasshouse experiments. When NaPR-1- and NaThionin-silenced plants were transplanted into the plant's native habitat in the Great Basin Desert of Utah, opportunistic Pseudomonas spp. performed better on NaThionin-silenced plants compared with $\mathrm{NaPR}$-1-silenced and wild-type (WT) plants, and accounted for increased plant mortality. The native herbivore community of $N$. attenuata attacked both $\mathrm{NaPR}-1-$ and $P R-13 / \mathrm{NaThionin}$-silenced plants to the same degree as it did in WT plants, indicating that neither PR protein provides resistance to herbivores. Although $P R-1$ is generally considered a marker gene of disease resistance, we found no evidence that it has an antimicrobial function. In contrast, $\mathrm{PR}-13 / \mathrm{NaThionin}$ is clearly an ecologically relevant defense protein involved in resisting pathogens in $N$. attenuata.
\end{abstract}

Plants are challenged by a number of disease-causing pathogens. To resist such pathogens, plants have evolved various defense strategies which allow them to recognize a pathogen and mount a comprehensive defense. Often, plants' disease resistance is inducible; that is, initiated in the host plant after recognition of a specific pathogen (avirulent pathogen). In this interaction, the plant's resistance $(R)$-gene-encoded protein recognizes the protein encoded by the pathogen's avirulence $(A V R)$ gene and initiates rapid defense responses. These include the hypersensitive response (HR) (rapid localized cell death at

Corresponding author: I. T. Baldwin; Fax: +49-3641-571102, E-mail: baldwin@ice.mpg.de

Current address of C. Haas: University of Technology and Economics, Dresden, Germany.

* The $e$-Xtra logo stands for "electronic extra" and indicates that six supplemental figures and two supplemental tables are published online and that Figures 2 and 6 appear in color online. the site of infection), an oxidative burst, and the increased expression of pathogenesis-related $(P R)$ genes. The HR restricts the growth of bacteria within the infection site as a first line of defense, and increased expression of $P R$ genes, many of which typically encode antimicrobial proteins, represent additional barriers to the growth and spread of a pathogen (van Loon et al. 2006). This type of race-specific disease resistance is known as "host resistance" or "gene-for-gene resistance" (Mysore and Ryu 2004). The lack of the host plant's $R$ gene to recognize the pathogen's $A V R$ gene (virulent pathogen) leads to the rapid spread of the pathogen beyond the site of infection and results in disease (Bent et al. 1992; Hofius et al. 2007).

In addition to $R$-Avr-induced recognition, pathogens also are recognized through pathogen-associated molecular patterns (PAMPs) (Gomez-Gomez and Boller 2002; Mysore and Ryu 2004). Once the pathogens are recognized, several defense responses are activated through a mitogen-activated protein kinase cascade (Asai et al. 2002) that is distinct from $R$-gene-triggered recognition in gene-for-gene or host resistance (Mysore and Ryu 2004). These responses ultimately lead to altered cytoplasmic $\mathrm{Ca}^{2+}$ levels, reactive oxygen species (ROS), nitric oxides (NO), and increased transcripts of many genes involved in pathogen resistance, including $P R$ genes (Jonak et al. 2002; Nurnberger and Lipka 2005; Vernooij et al. 1994; Zhang and Klessig, 2001).

Despite the fact that many studies use PR gene or protein expression as markers for pathogen-induced systemic-acquired resistance (SAR), the biological activity and the mode of action of many PR proteins remain elusive (van Loon et al. 2006). What is known about the few characterized PR proteins is that they can act as antimicrobial compounds helping the plant resist pathogen growth. For example, ectopically expressing thaumatin-like PR-5 increased the tolerance of rice to Rhizoctonia solani and Phytophthora citrophthora (Fagoaga et al. 2001), and ectopically expressing PR-2 ( $\beta$-1,3-glucanase) and PR-3 (chitinase) in carrot plants improved their resistance to PHYTOPHTHORA infestans (Bachmann et al. 1998). One of the most commonly used markers for pathogen defense activation is $P R-1 . P R-1$ is induced following pathogen infection through the action of signaling compounds such as salicylic acid (SA), jasmonic acid (JA), or ethylene (Niki et al. 1998; Ward et al. 1991). However, neither tomato nor tobacco plants engineered to constitutively express different forms of $P R-1$ have noticeably increased resistance to PHYTOPHTHORA infestans (van Loon et al. 2006). The lack of evidence supporting an antimicrobial function for PR-1 continues to puzzle researchers who study disease resistance in plants. In contrast, PR-12 and PR-13 - also known as defensins and Thionins, respectively-have been well studied and are known to permeate pathogen membranes (Edreva 2005). These proteins (Thionins, 
in particular) are inducibly expressed in leaves, whereas constitutive levels vary greatly among different tissues. $P R$ 13/Thionin is found at higher levels in floral tissues. Enhanced resistance to seed-transmitted bacterial diseases was reported in rice that was transformed to express an oat Thionin (Iwai et al. 2002). Expression in tobacco plants of a barley Thionin gene reduced lesion size when the plants were challenged with two strains of Pseudomonas syringae (Carmona et al. 1993; Florack et al. 1993). Although PR-13/Thionins are known to be effective antimicrobial proteins, two issues remain unexplored: a demonstration of PR-13/Thionin antimicrobial properties under natural conditions and their potential function as an antiherbivory defense, which is suggested by their elicitation by JA treatment and herbivore attack. For example, a 5$\mathrm{kDa}$ monomeric form of sorghum $\gamma$-Thionin (hordoThionin), which is expressed in response to insect attack, was found to be capable of inhibiting insect $\alpha$-amylases (Chandrashekar and Satyanarayana 2006).

Nicotiana attenuata is an annual plant native to the southwestern United States. N. attenuata germinates from dormant seed banks in response to factors in smoke following fires in the desert. The nutrient-rich soil that is found after fires facilitates the growth of many competitors of $N$. attenuata and also of the populations of the herbivores and pathogens which subsequently recolonize burned areas. During this process, $N$. attenuata may encounter opportunistic, virulent pathogens and we were interested in understanding the ecological significance of elicited PR proteins. We cloned two $N$. attenuata $P R$ genes, $P R$ - $1 a$ (henceforth NaPR-1) and PR-13/Thionin (henceforth NaThionin), which were highly elicited when plants were infected with $P$. syringae pv. tomato DC3000, which is a virulent strain of $N$. attenuata. To determine whether $\mathrm{NaPR}-1$ and NaThionin mediate $N$. attenuata's basal resistance to $P$. syringae pv. tomato DC3000 and herbivores, we generated transgenic lines in which $\mathrm{NaPR}-1$ and NaThionin gene expression were independently silenced by RNAi and tested the plants in both the glasshouse and their native habitat, the Great Basin Desert in Utah.

\section{RESULTS}

\section{Characterization of NaPR-1 and NaThionin in wild-type and transgenic $N$. attenuata plants silenced for PR-1 and Thionin.}

From SA-treated leaves of wild-type (WT) N. attenuata, we cloned the $N$. attenuata PR-1 (NaPR-1) full-length gene (Supplementary Fig. S1A). The nucleotide sequence of $\mathrm{Na} P R-1$ is 94\% identical to the acidic $P R-1$ identified in cultivated tobacco (accession number X12485), but varies significantly from $P R-1 \mathrm{~s}$ identified in other plant species. In addition, we also cloned a partial $N$. attenuata $P R-1$ gene fragment $(\mathrm{Na} P R$ $1 b$ ) from WT $N$. attenuata leaves after wounding plus oral secretion treatment $(\mathrm{W}+\mathrm{OS})$ of a solanaceous specialist herbivore, Manduca sexta larvae, which shows $96 \%$ homology to $N$. tabacum basic PR-1 (accession number X66942). In comparison with $\mathrm{NaPR}-1, N a P R-1 b$ is weakly induced following $P$. syringae pv. tomato DC3000 (Supplementary Fig. S2). Because acidic $P R-1$ and basic $P R-1$ in tobacco are known to be SAand JA-responsive, respectively (Niki et al. 1998), and given that $\mathrm{W}+\mathrm{OS}$ treatment is known to elicit increases in JA (Halitschke and Baldwin 2003), we assumed that, despite their $80 \%$ identity, NaPR-1 but not NaPR-1b was involved in biotropic pathogen resistance. Therefore, we chose to silence $\mathrm{Na} P R-1$ rather than $\mathrm{Na} P R-1 b$ to study the role of $P R-1$ in mediating pathogen resistance in $N$. attenuata.

NaThionin (National Center for Biotechnology Information [NCBI] accession AY456268) was previously shown to be upregulated in WT $N$. attenuata plants after being attacked by M. sexta larvae (Lou and Baldwin 2004; Voelckel and Baldwin 2003). Some studies have also shown that plants usually have multiple copies of Thionins in their genomes (Garcia-Olmedo et al. 1998). Thus, we sought to isolate Thionins in N. attenuata using NaThionin-specific primers. After sequencing multiple clones, we found that, in addition to the predominant NaThionin previously isolated from herbivore-elicited WT $N$. attenuata leaves (accession number: AY456268), another NaThionin-like gene (NaThionin1) was found which differs slightly from NaThionin. In comparison with NaThionin, NaThioninl is weakly induced following P. syringae pv. tomato DC3000 (Supplementary Fig. S3). Due to three nucleotide deletions at different positions in the NaThioninl sequence, the open reading frame (ORF) contains a frame shift and, because these deletions do not introduce a termination codon, NaThionin1 and NaThionin code for two different Thionin proteins.

To determine whether NaPR-1 and NaThionin are involved in pathogen-induced responses, we analyzed the transcript accumulation patterns of $\mathrm{NaPR}-1$ and NaThionin in WT plants after $P$. syringae pv. tomato DC3000 infection. The quantitative real-time reverse-transcriptase polymerase chain reaction (qRT-PCR) results showed that both $\mathrm{NaPR}-1$ and NaThionin transcript accumulation increased more than twofold $24 \mathrm{~h}$ after $P$. syringae pv. tomato DC3000 inoculation and remained almost constant for $72 \mathrm{~h}$ (Fig. 1) (analysis of variance [ANOVA] $\left.F_{19,39}=22.25, P<0.001\right)$. In the water-treated WT plants, $\mathrm{Na} P R-1$ transcripts were not detected, whereas basal levels of NaThionin transcripts were detectable.

To investigate the functions of NaPR-1 and NaThionin, independent transgenic lines irPR-1 and irThionin, with reduced transcripts of endogenous $\mathrm{Na} P R-1$ and NaThionin, respectively, were produced by transforming plants with a pRESC5 vector containing an inverted-repeat construct of partial $\mathrm{Na} P R$ 1 and NaThionin sequences. Two independent lines for ir $P R-1$ and irThionin were obtained by screening transgenic plants on hygromycin. Each line harbored a single transgene inserted in its genome as determined by segregation analysis and Southern blotting (Supplementary Fig. S4A and B). Levels of NaPR1 and NaThionin transcripts after treatment with SA and with $\mathrm{W}+\mathrm{OS}$ were significantly decreased (nearly $50 \%$ ) in the transformed ir $P R-1$ lines (172 and 217) (ANOVA $F_{2,6}=19.18, P=$ 0.002 ) and in the irThionin lines (76 and 96) (ANOVA $F_{2,6}=$ $74.89, P<0.001)$, respectively.

\section{NaThionin, but not NaPR-1, mediates resistance to $P$. syringae pv. tomato $\mathrm{DC} 3000$.}

First, we determined whether $P$. syringae pv. tomato DC3000 is virulent and able to produce characteristic disease lesions but not HR in $N$. attenuata. We dipped an entire leaf in $P$. syringae pv. tomato DC3000 (resuspended in Silwett L-77) $\left(1 \times 10^{8}\right.$ cells $\left./ \mathrm{ml}\right)$ as described by Katagiri and associates (2002). P. syringae pv. tomato DC3000-inoculated leaves showed patches of characteristic leaf spot disease lesions but without HR from day 3 onward (Fig. 2A). As the disease progressed, the whole leaf showed disease lesions which eventually became necrotic 14 days after inoculation (Fig. 2A). To determine if NaPR-1 and NaThionin restrict the growth of $P$. syringae pv. tomato DC3000 in N. attenuata, we infiltrated single leaves in five replicate pairs each of WT plants/irPR-1 lines (172 and 217) and WT plants/irThionin lines (76 and 96) with a known amount of $P$. syringae pv. tomato DC3000 (resuspended in sterile water) $\left(100 \mu \mathrm{l}\right.$ of $\left.1 \times 10^{5} \mathrm{cell} / \mathrm{s} / \mathrm{ml} / \mathrm{spot}\right)$ in two separate experiments. As a control, we performed a mock treatment, inoculating other plants with sterile water. Neither WT nor any lines showed lesions after water treatment until 
the end of our experiment (14 days) (Fig. 2B). On the other hand, lesions were apparent from day 4 onward in the plants inoculated with $P$. syringae pv. tomato DC3000 (Fig. 2C). The spot where the syringe pierced the leaf became necrotic, while the area surrounding this inoculation site showed the characteristic leaf spot disease lesions but not HR. WT plants and irPR-1 lines (172 and 217) revealed similar symptoms, while irThionin plants (76 and 96) showed larger lesions and contained more $P$. syringae pv. tomato DC3000 per unit area than did WT plants and irPR-1 lines (172 and 217) 1 week after inoculation (Fig. 2B and C). After 3 weeks, the leaves were completely necrotic in irThionin plants (76 and 96). To quantify the spread of disease and the greater susceptibility of irThionin plants (76 and 96) compared with both WT and ir $P R-1$ plants, we measured lesion diameter 6,9 , and 12 days after $P$. syringae pv. tomato DC3000 inoculation. Even after 12 days, we found no significant differences in lesion diameters between WT plants and irPR-1 lines (172 and 217) (Fig. 3A, left panel; ANOVA $\left.F_{2,12}=1.08, P=0.367\right)$; lesion diameters in irThionin lines (76 and 96), on the other hand, were significantly larger (by at least $63 \%$ on day 12) than in those on WT plants (Fig. 3A, right panel; ANOVA $F_{8,39}=28.45, P<0.0001$ ). To determine if the increased lesion diameter in irThionin lines (76 and 96) was associated with increased bacterial growth, we counted the CFU of $P$. syringae pv. tomato DC3000 in $P$. syringae pv. tomato DC3000-inoculated WT, irPR-1 (172 and 217), and irThionin plants (76 and 96) from a standardized amount of tissue $1 \mathrm{~cm}$ from the infiltration sites. Consistent with observations of lesion diameter, no differences in the CFU (log transformed) between WT and irPR- 1 plants (172 and 217) was observed even after 9 days (Fig. 3B, left panel; ANOVA $\left.F_{2,12}=0.319, P=0.733\right)$. In contrast, CFU were greater (by at least 27\%) on irThionin plants (76 and 96) than on WT plants from day 4 onward (Fig. 3B, right panel; ANOVA $\left.F_{8,36}=30.94, P<0.0001\right)$. We observed that, on day 1, the number of CFU on irThionin plants (76 and 96) was slightly higher (but not statistically significant) than on WT plants (Fig. 3B, right panel). Therefore, we repeated the experiment. Consistent with the earlier observation, we found increased CFU counts on P. syringae pv. tomato DC3000inoculated irThionin plants (76 and 96) in comparison with $P$. syringae pv. tomato DC3000-inoculated WT plants only on day 4 but not on day 0 (Fig. 3B, right panel: inset; ANOVA $\left.F_{8,36}=73.01, P<0.0001\right)$. Increased lesion diameter and CFU on irThionin plants (76 and 96) clearly suggest that NaThionin plays a crucial role in limiting $P$. syringae pv. tomato DC3000 growth, whereas $\mathrm{NaPR}-1$ does not.

To correlate increased $P$. syringae pv. tomato DC3000 susceptibility in NaThionin-silenced lines with reduced NaThionin levels, we used qRT-PCR analysis to quantify NaThionin and NaPR- 1 transcript levels. NaPR-1 and NaThionin transcripts at 24,48 , and $72 \mathrm{~h}$ post $P$. syringae pv. tomato DC3000 inoculation were significantly lower in irPR-1 lines (172 and 217) (by at least 50\%) (Fig. 4A; ANOVA $F_{35,72}$ $=29.1, P<0.0001)$ and irThionin lines (76 and 96) (by at least $45 \%$ ), respectively (Fig. 4B; ANOVA $F_{35,72}=75.0, P<0.0001$ ), in comparison with their respective levels in the WT. We did not observe any influence of $\mathrm{NaPR}-1$ silencing on NaThionin transcript accumulation in ir $P R-1$ lines (172 and 217) (Fig. 4A, inset; ANOVA $F_{11,24}=8.33, P<0.0001$ ) or NaThionin silencing on $\mathrm{Na} P R-1$ transcript accumulation in irThionin lines (Fig. 4B, inset; ANOVA $F_{11,24}=35.4 .0, P<0.0001$ ). We conclude that, although NaThionin silencing in $N$. attenuata increases a plant's susceptibility to $P$. syringae pv. tomato DC3000, silencing NaPR-1 does not. Moreover, $\mathrm{Na} P R-1$ and NaThionin transcript accumulation are independently regulated in N. attenuata.

\section{P. syringae pv. tomato DC3000-elicited SA} does not differ among WT, irPR-1, and irThionin plants.

A causal link between the expression of $P R$ genes and SA production is suggested from work showing that endogenously produced or exogenously applied SA is necessary to elicit many PR genes (van Loon et al. 2006; Vernooij et al. 1994).

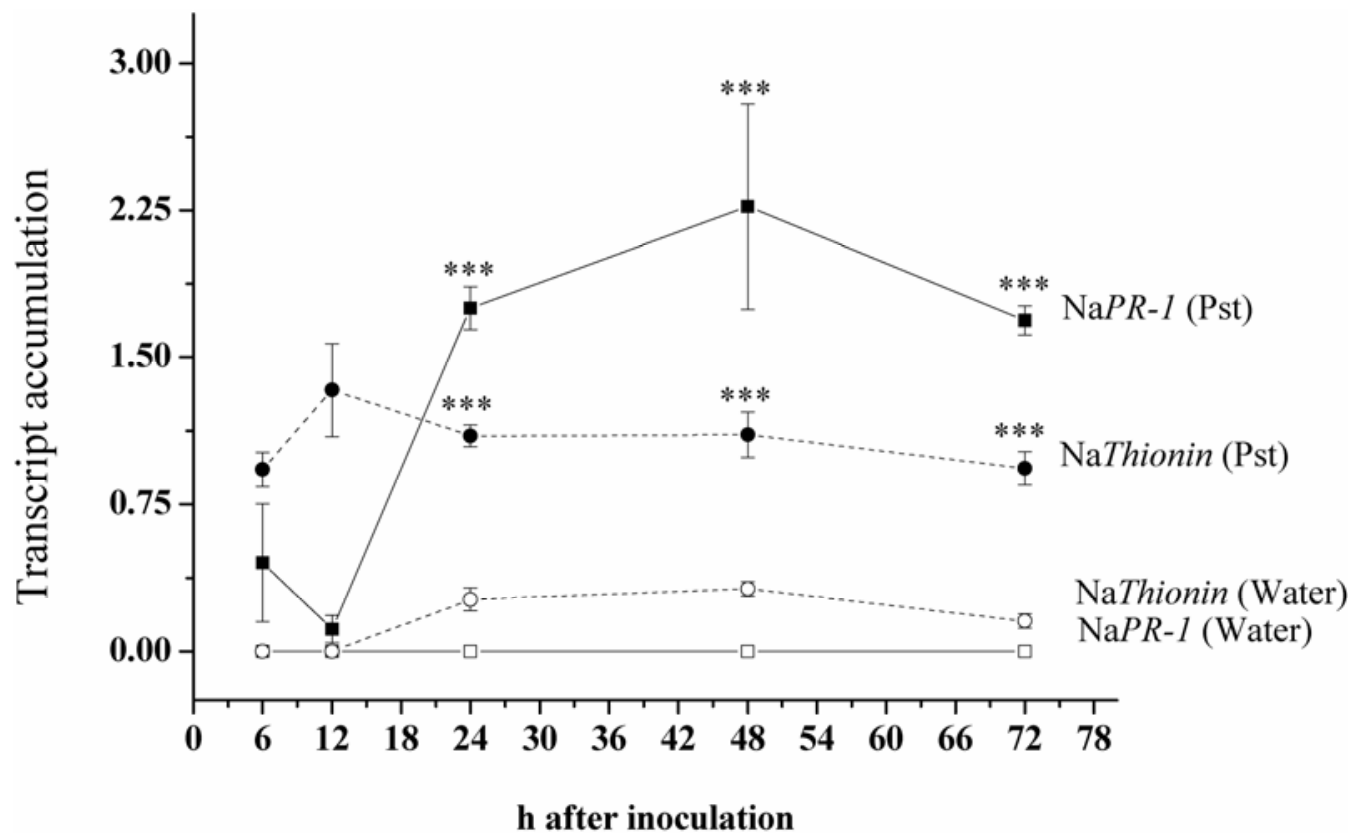

Fig. 1. Pseudomonas syringae pv. tomato DC3000 inoculation strongly increases NaPR-1 and NaThionin transcripts in wild-type (WT) Nicotiana attenuata. Quantitative real-time reverse-transcriptase polymerase chain reaction was used to analyze NaPR-1 and NaThionin transcript accumulation in WT $N$. attenuata plants in response to inoculation with $P$. syringae pv. tomato DC3000 $\left(1 \times 10^{5}\right.$ cells $\left./ \mathrm{ml}\right)$ or water. Values are mean $( \pm$ standard error $)$ of NaPR- 1 and NaThionin transcripts from three replicate plants per treatment normalized to the transcript abundance of actin, which is unregulated under these conditions. Asterisks indicate significant differences in NaPR-1 and NaThionin transcript accumulation between P. syringae pv. tomato DC3000-inoculated and waterinoculated WT plants at the designated time, $P<0.001(* * *)(n=3)$. 
We analyzed free SA in $P$. syringae pv. tomato DC3000-inoculated plants to understand whether $P$. syringae pv. tomato DC3000 inoculation increases SA and whether NaPR-1 or NaThionin silencing influences the $P$. syringae pv. tomato DC3000-elicited increase in SA accumulation. In two separate experiments, although no significant differences in SA levels were found between WT and transgenic plants that had been inoculated with $P$. syringae pv. tomato DC3000, very high levels of SA (nearly 9.0-fold after $24 \mathrm{~h}$ ) were detected after WT/irPR-1 lines (172 and 217) (Supplementary Fig. S5) ANOVA $F_{18,35}=$ 22.6, $P<0.0001$ ) and WT/irThionin lines (76 and 96) (ANOVA $\left.F_{18,35}=26.5, P<0.0001\right)$ were inoculated with $P$. syringae pv.
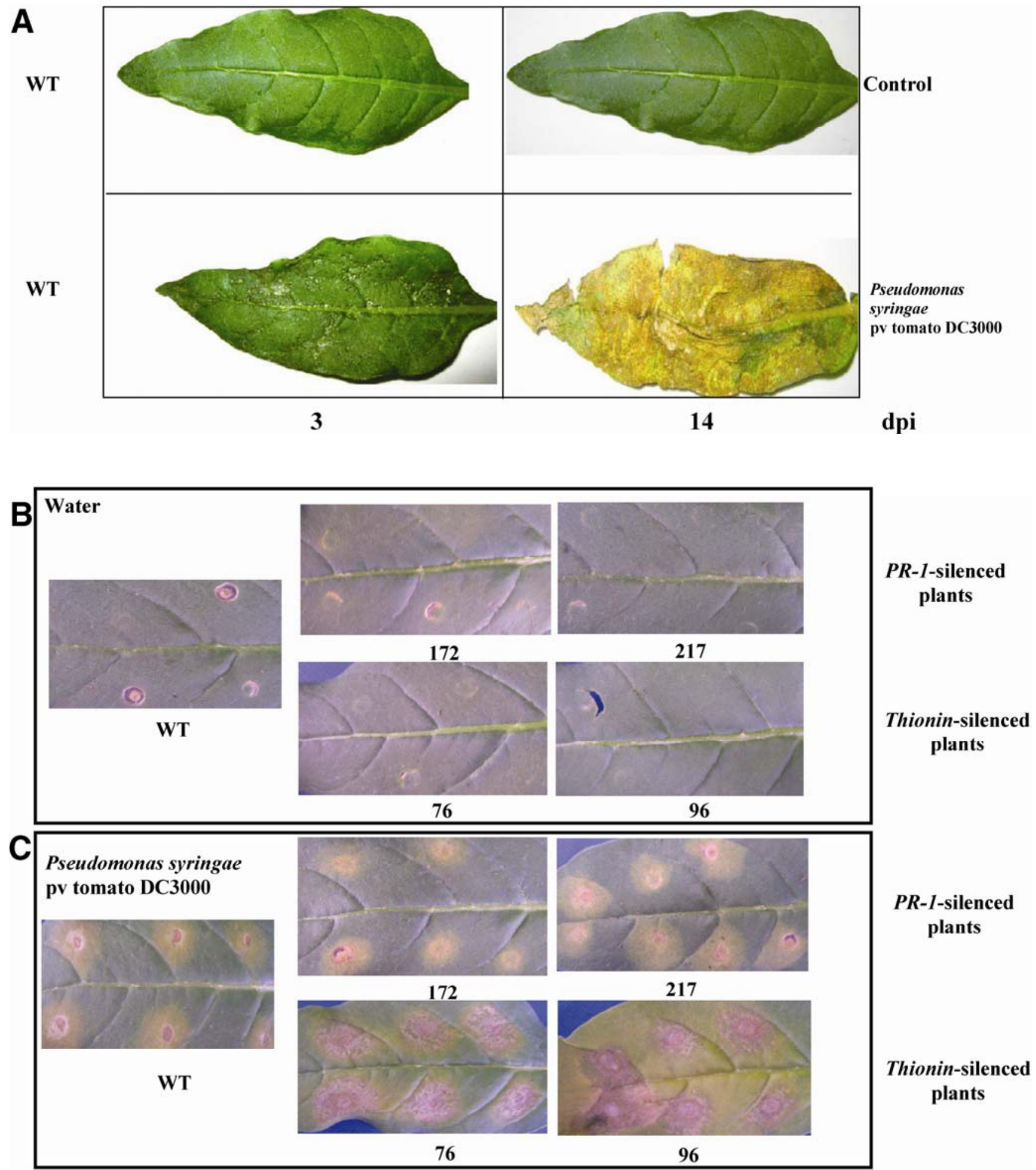

Fig. 2. NaThionin-silenced Nicotiana attenuata plants are more susceptible to Pseudomonas syringae pv. tomato DC3000 infection than are NaPR-1silenced plants. A, Characteristic disease lesions in wild-type (WT) N. attenuata leaves caused by the virulent $P$. syringae pv. tomato DC3000. Intact leaves were dipped in $0.05 \%$ Silwett L-77 solution containing P. syringae pv. tomato DC3000 $\left(1 \times 10^{8}\right.$ cells $\left./ \mathrm{ml}\right)$ containing solution for $30 \mathrm{~s}$. Plants were further monitored for 14 days. Differences in the lesion size of WT, irPR-1, and irThionin N. attenuata leaves in response to inoculation with $\mathbf{B}, 100 \mu 1 /$ spot of water or $\mathbf{C}, 100 \mu \mathrm{l} / \mathrm{spot}$ of $P$. syringae pv. tomato DC3000 cell suspension $\left(1 \times 10^{5}\right.$ cells $\left./ \mathrm{ml}\right)$. The pictures were taken 8 days after inoculation. 
tomato DC3000. This suggests that $N$. attenuata can recognize $P$. syringae pv. tomato DC 3000 and activates basal resistance responses. Given that neither $\mathrm{NaPR}-1$ nor NaThionin silencing influenced SA production after $P$. syringae pv. tomato DC3000 inoculation, $\mathrm{NaPR}-1$ and NaThionin are either downstream of SA or independent of it. We also analyzed JA contents in these plants and did not detect any increases in JA levels in WT or transgenic plants at any time $(6,24$, and $48 \mathrm{~h})$ after $P$. syringae pv. tomato DC3000 infection, which suggests that JA is not important in the $N$. attenuata-P. syringae pv. tomato DC3000 interaction.
Microarray analyses reveal transcriptional responses
consistent with an antimicrobial function for Thionin.

Thionins interact directly with membranes, creating patches or rafts which eventually increase membrane permeability; however, some studies suggest that they can also function as regulatory proteins that inhibit protein synthesis, interact directly with mRNA, or influence $\mathrm{Ca}^{2+}$ ion permeability (GarciaOlmedo et al. 1998; Stec 2006). We used a custom microarray to determine whether silencing NaThionin influenced the expression of genes involved in these regulatory processes. The microarray contained genes involved in $\mathrm{Ca}^{2+}$ signaling, cell
A

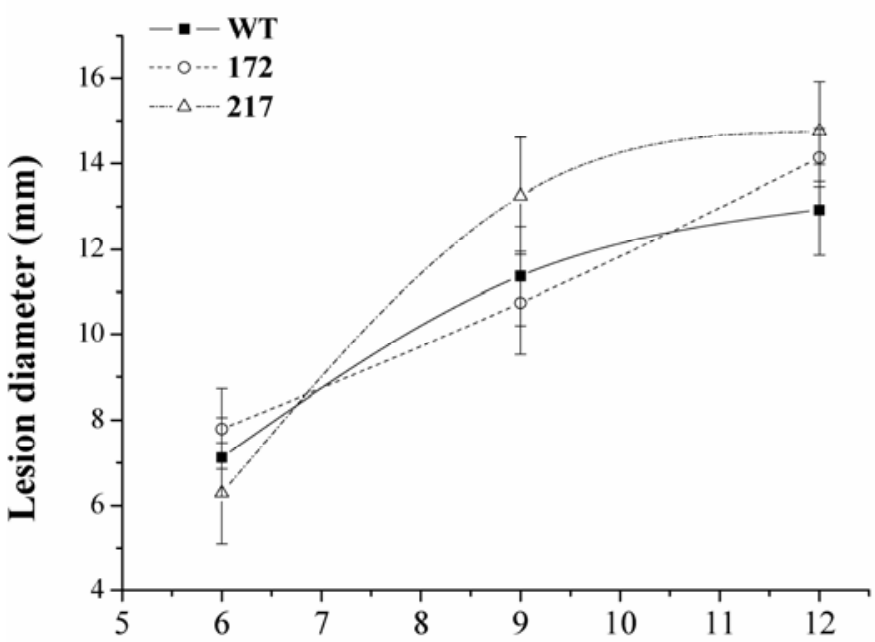

\section{Thionin-silenced plants}

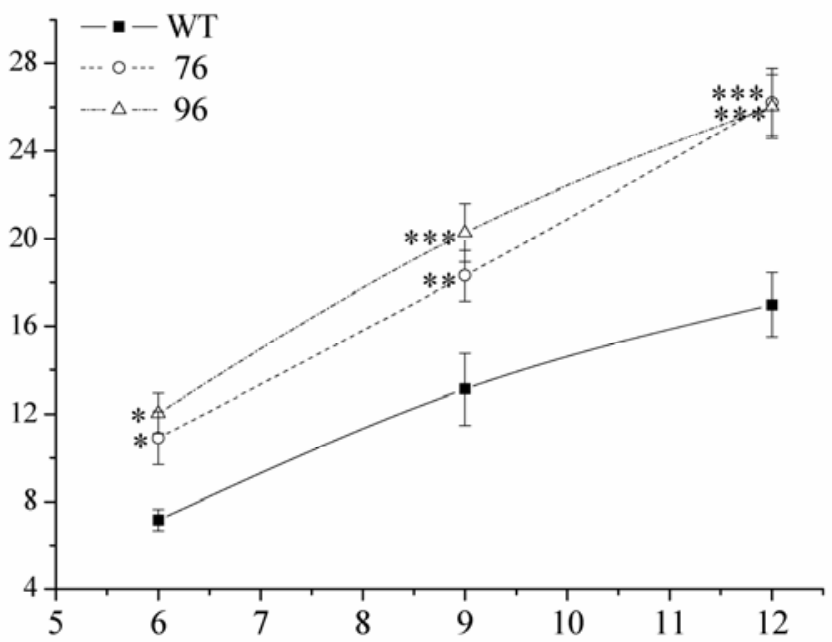

B
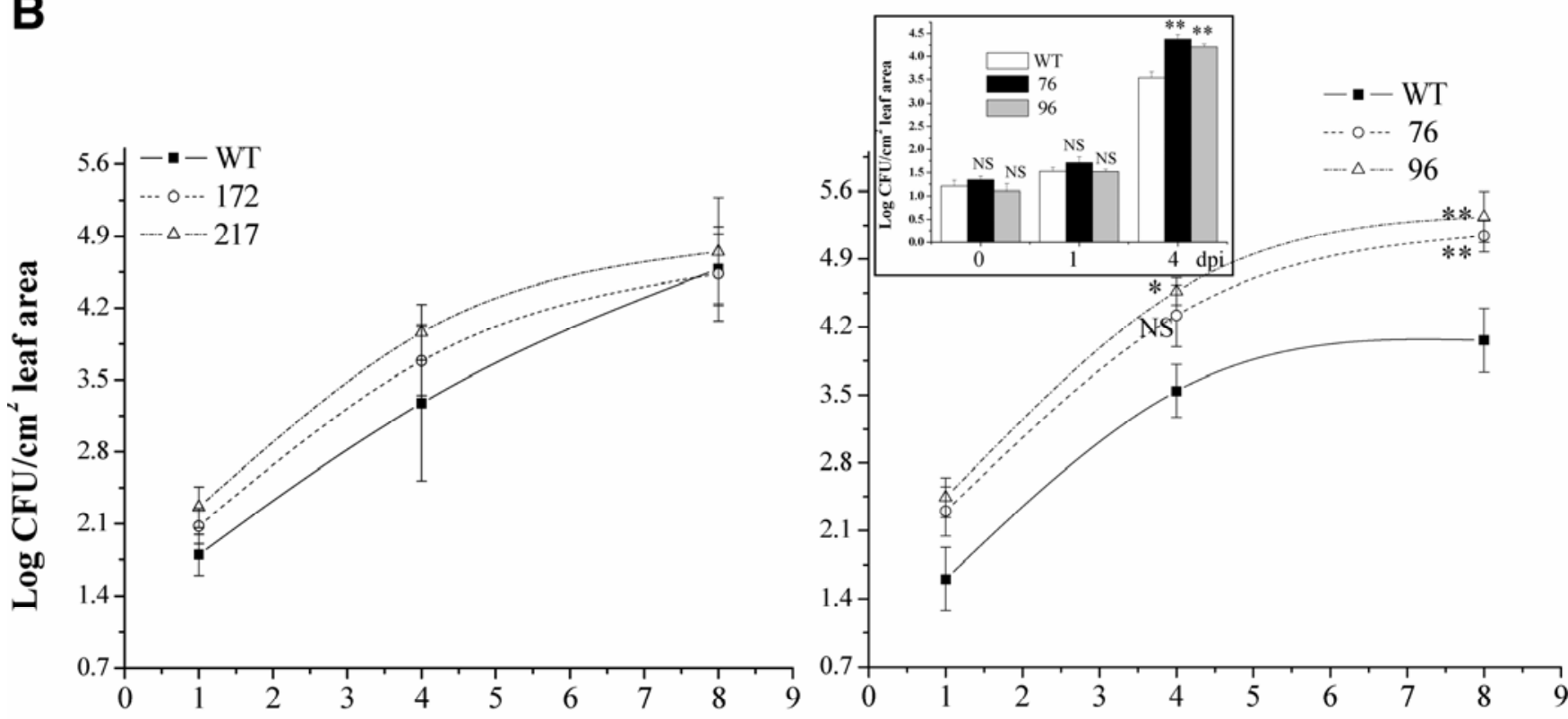

\section{d after inoculation}

Fig. 3. Quantification of disease severity and in vivo Pseudomonas syringae pv. tomato DC 3000 growth in Nicotiana attenuata wild-type (WT) plants and plants silenced in NaPR-1 and NaThionin demonstrate that NaThionin but not NaPR-1 functions as an antimicrobial protein against $P$. syringae pv. tomato DC3000. A, Mean ( \pm standard error [SE]) lesion diameters of $P$. syringae pv. tomato DC3000-inoculated WT and irPR-1 lines (172 and 217, left panels) and WT and irThionin (76 and 96, right panels). The central necrotic region as well as the outer chlorotic region was measured using a slide caliper. B, Mean ( \pm SE) CFU of $P$. syringae pv. tomato DC3000-inoculated WT and irPR-1(172 and 217, left panel) and WT and irThionin (76 and 96, right panel) N. attenuata leaves. Inset: mean ( \pm SE) CFU of $P$. syringae pv. tomato DC3000-inoculated WT and irThionin (76 and 96) in a separate experiment. To record the CFU, surface-sterilized leaf discs $\left(1 \mathrm{~cm}^{2}\right)$ were ground in $1 \mathrm{ml}$ of sterile water and $40 \mu$ of supernatant was spread on plates containing Luria-Bertani agar. Colonies were counted after $14 \mathrm{~h}$ of incubation at $28^{\circ} \mathrm{C}$. Asterisks indicate significant differences among $P$. syringae pv. tomato DC3000-inoculated WT plants and the transgenic plants at a given time point $(*$ and $* *=P<0.05$ and 0.01 , respectively) $(n=5)$. 
division, cell-cell signaling, cell wall cross-linking, all known PR genes, genes related to phytohormone biosynthesis, heat shock proteins, and several transcription factors. (Supplementary Table S1). We hybridized arrays with cDNA prepared from RNA extracted from irThionin lines (76 and 96) (treatment) and WT plants (control) that had been inoculated with $P$. syringae pv. tomato DC3000 for $24 \mathrm{~h}$. RNA samples were extracted from three biological replicates of WT plants and
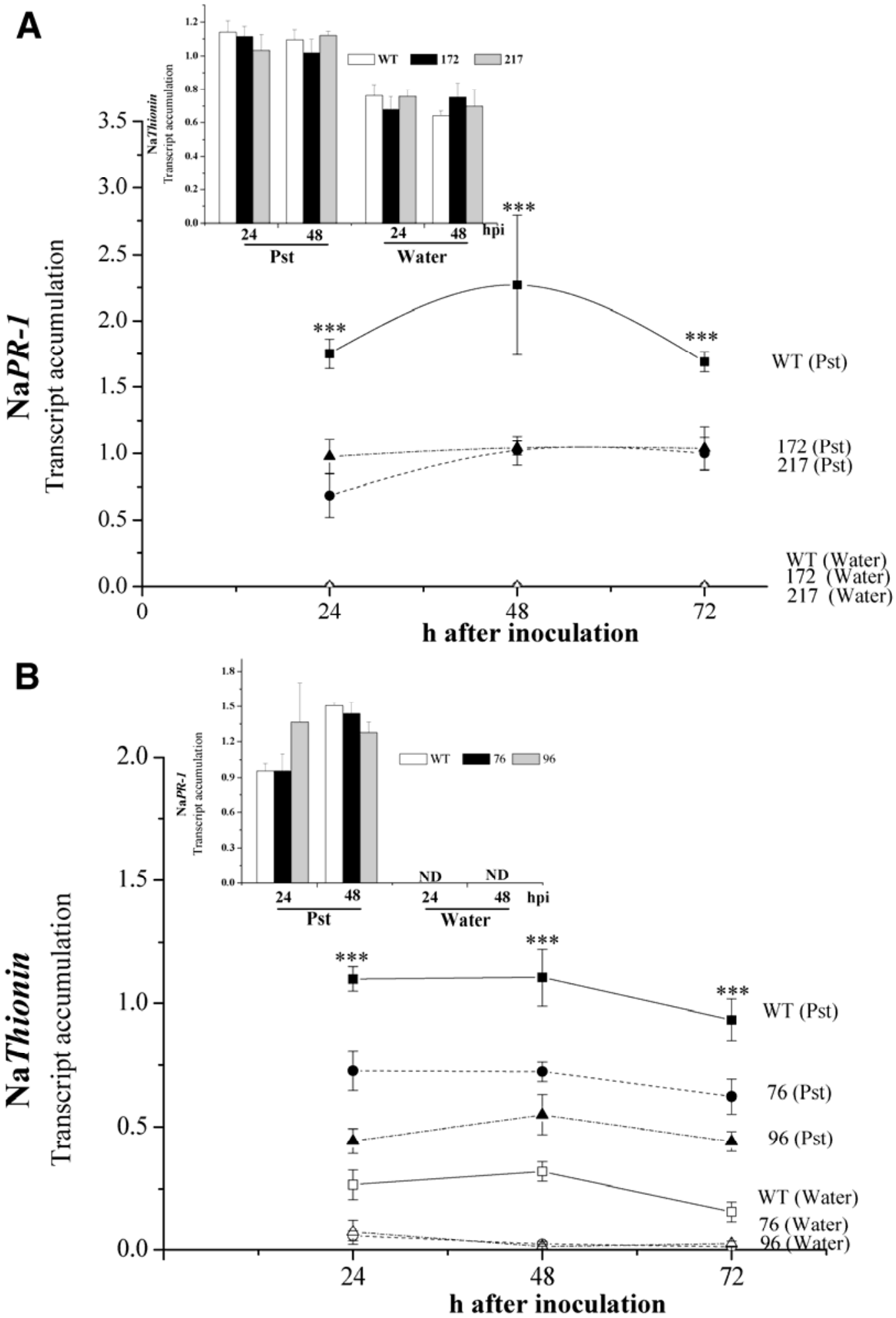

Fig. 4. Independently silencing NaPR-1 and NaThionin in transformed plants. A, Mean ( \pm standard error [SE]) levels of NaPR-1 transcripts in wild-type (WT) and two irPR-1 lines (172 and 217) of Nicotiana attenuata. Inset: mean ( \pm SE) NaThionin transcript levels in WT plants and irPR-1 lines (172 and 217). B, Mean ( \pm SE) of NaThionin transcript levels in WT and two irThionin lines (76 and 96) of $N$. attenuata. Inset: Mean ( \pm SE) NaPR-1 transcript levels in WT plants and irThionin lines (76 and 96) of $N$. attenuata. Transcripts were analyzed by quantitative real-time reverse-transcriptase polymerase chain reaction. Plants were inoculated with $100 \mu \mathrm{l} / \mathrm{spot}$ of $1 \times 10^{5}$ cells $/ \mathrm{ml}$ of $P$. syringae pv. tomato DC3000 or $100 \mu \mathrm{l}$ of water. cDNA (100 ng) from three replicate plants per treatment was used in the analysis. Constitutively unregulated actin was used for normalization. Asterisks indicate significant differences among P. syringae pv. tomato DC3000inoculated WT plants and the transgenic plants at a given time point (** and $* * *=P<0.01$ and 0.001 , respectively) $(n=3)(\mathrm{ND}=$ not detected). 
irThionin lines (76 and 96), reverse transcribed and hybridized, respectively, to three replicate microarrays. Of the 1,421 genes spotted on each microarray, only 9 were differentially regulated as a result of silencing NaThionin (Fig. 5A). As expected, NaThionin was significantly downregulated in two independently transformed lines. We found seven genes downregulated along with NaThionin. Two genes, HRGP and PAP (a cell wall cross-linker and a fibrillin), can be associated with pathogen defense; Agpl (glucose 1-phosphatase), ASN1 (nitrogen metabolism), and $P D X 2$ (amido transferase) are mainly primary metabolism genes. Only two genes were upregulated: $A P H$ (which is involved in extracellular nucleotide phosphate hydrolysis) and $G T$ (an enzyme involved in conjugating glutathione to various electrophilic compounds). $H R G P$ and $P A P$ gene expression was further verified by RT-PCR (Fig 5B). These results suggest that NaThionin silencing does not markedly affect cellular signaling processes and that its function is likely limited to direct defense.

\section{NaThionin-silenced plants are susceptible to pathogens} but not herbivores in nature.

We tested the hypothesis that NaThionin protects $N$. attenuata from opportunistic pathogens by transplanting size-matched
WT, irPR-1 (172), and irThionin (96) pairs into $N$. attenuata's native habitat in the Great Basin Desert and compared the extent of damage on all genotypes. The transgenic plants and the WT plants showed no growth differences at the time of transplantation. The percentage of total herbivore damage increased significantly in all plants (day 1 to day 5) but no statistical differences in total herbivore damage among all plants were observed on any day (Fig. 6A; ANOVA $F_{8,105}=1.984, P=0.06$ ). A similar trend was also seen when we evaluated damage caused by individual herbivores; namely, grasshoppers (Fig. 6B; ANOVA $F_{8,105}=2.83, P=0.07$ ) and flea beetles (Ephitrix spp.) (Fig. 6C; ANOVA $F_{8,105}=0.474, P=0.87$ ). Notably, irThionin (96) plants showed significantly more damage caused by pathogen infections (2.3-fold on day 23 and day 25) than the irPR-1 (172) and WT plants (Fig. 6D and F; ANOVA $\left.F_{8,105}=3.218, P=0.002\right)$. The disease symptoms appeared 2 days after a brief rain, which may have vectored soil bacteria to leaves that were in contact with the soil via raindrop splash. We subsequently identified two Pseudomonas spp. (an unidentified species of Pseudomonas strain 4 and $P$. jessenii) from the infected field samples (Supplementary Table S2). Only Pseudomonas sp. strain 4 was pathogenic when inoculated into the WT $N$. attenuata plants grown in the glasshouse (Rayapuram

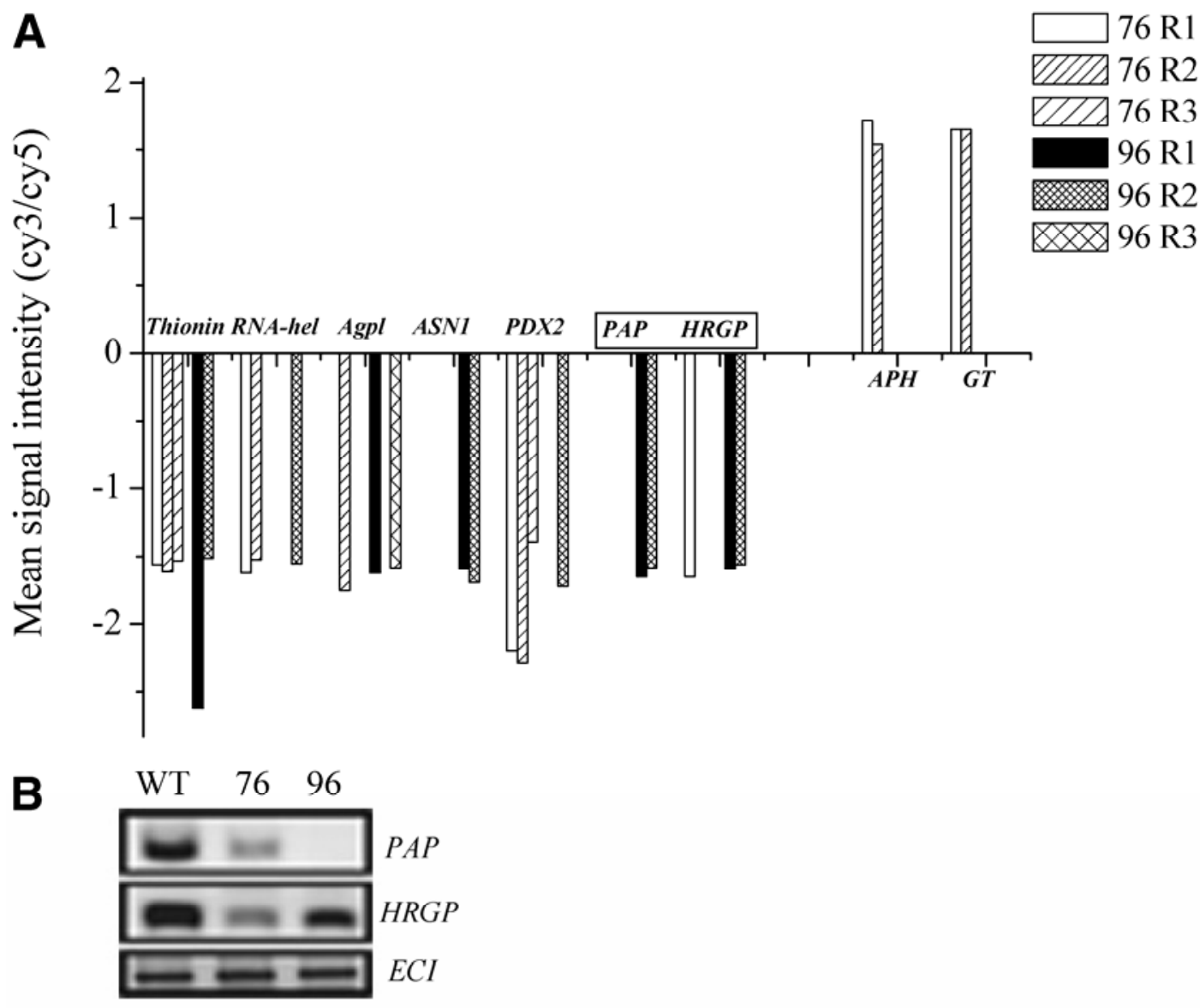

Fig. 5. Microarray analysis of NaThionin-silenced plants does not reveal large-scale transcriptional changes in Pseudomonas syringae pv. tomato DC3000infected Nicotiana attenuata plants, which argues against a secondary role for Thionin apart from its antimicrobial role. A microarray experiment was designed to analyze changes in the gene expression in NaThionin-silenced plants when plants were inoculated with P. syringae pv. tomato DC3000 for $24 \mathrm{~h}$ cDNA derived from $P$. syringae pv. tomato DC3000-inoculated irThionin lines (76 and 96) labeled with Cy3 was hybridized against cDNA derived from similarly infected wild-type (WT) N. attenuata plants labeled with Cy5. A, Mean signal intensities of differentially regulated genes in P. syringae pv. tomato DC3000-inoculated irThionin lines (76 and 96). The criterion for a gene to be classified as differentially regulated was \pm 1.5 . The genes that were differentially regulated are RNA- $h$ (RNA-helicase), Agpl (glucose-1-phosphate adenylyltransferase), ASN1 (asparagine synthetase 1), PDX2 (pyridoxine synthesis gene 2), PAP (plastid-lipid-associated protein), HRGP (hydroxyproline-rich glycoproteins), APH (alkaline phosphatase), and $G T$ (glutathione $S$-transferases), $R 1, R 2$, and $R 3$ refer to replicates. B, Verification of the microarray results by reverse-transcriptase polymerase chain reaction. Two downregulated genes, $P A P$ and HRGP, which are highly implicated in pathogen defense, are downregulated in the irThionin lines (76 and 96), supporting the microarray results. An unregulated $E C I$ was used as a loading control. 
and Baldwin 2007). The differences in plant mortality among the genotypes were consistent with an ecological role of Thionin; irThionin (96) plants had a $90 \%$ higher mortality rate compared with irPR-1 (172) and WT plants (Fig. 6E; $\chi^{2}$ [df 2] = $31.75, P<0.001)$.
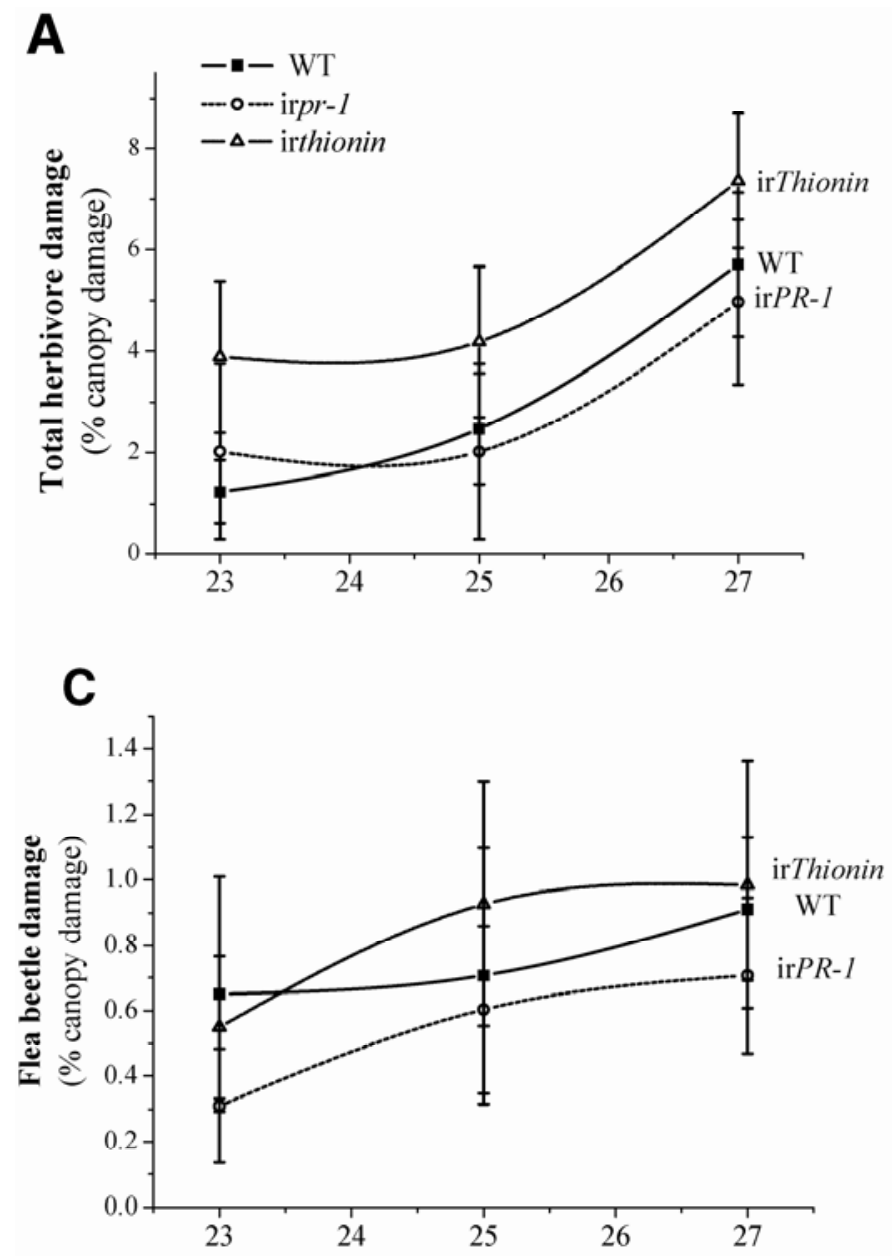

d after transplanting

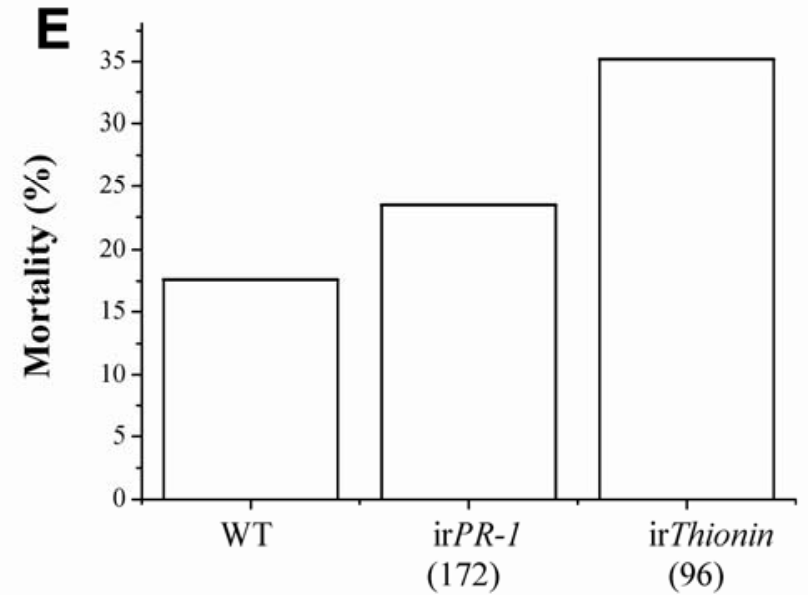

$\mathbf{F}$

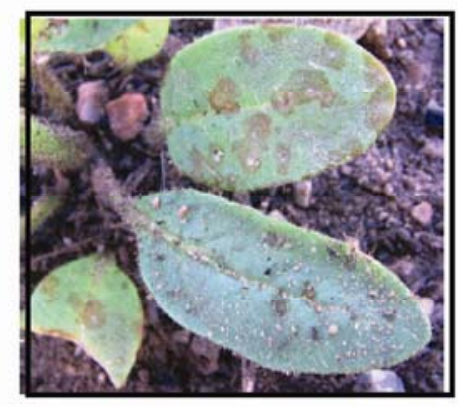

Fig. 6. Herbivore damage and disease severity of soilborne bacterial infection on size-matched triplets of Nicotiana attenuata wild-type (WT), irPR-1, and irThionin plants growing in their native habitat in the Great Basin Desert reveal NaThionin's ecological role as antimicrobial but not antiherbivore defense proteins. Mean ( \pm standard error) canopy damage caused by A, all herbivores; B, grasshoppers; C, flea beetles (Epitrix hirtipennis); D, damage caused by naturally occurring or soilborne bacteria (identified as Pseudomonas spp.); E, percentage of mortality of $N$. attenuata WT, irPR-1, and irThionin plants in their natural habitat; and F, example of bacterial (Pseudomonas spp.) symptoms observed under natural conditions. Damage was measured as a percentage of total canopy area per damaged plant 21,23 , and 25 days after plants were transplanted into the field. The asterisk $(*)$ indicates a significant difference between irThionin and WT/ir $P R-1$ at $P<0.05$ ( $n=17$ pairs). 
syringae pv. tomato DC3000-infected WT and irThionin lines (96 and 76). NaThionin expression in the systemic leaves of WT and NaThionin-silenced plants $72 \mathrm{~h}$ after $P$. syringae pv. tomato DC3000 infection followed the trend observed in the locally treated leaves (Supplementary Fig. S7) and, furthermore, no traces of $P$. syringae pv. tomato DC3000 in the systemic leaf were observed (data not shown). The presence of the WT protein at lower concentrations $(0.25$ and $0.12 \mathrm{mg}$ of total proteins) in the media inhibited the growth of $P$. syringae pv. tomato DC3000 more than a similar amount of protein from irThionin lines (96 and 76) (Fig. 7). The reduced growth of $P$. syringae pv. tomato DC3000 in the samples containing the WT plant protein is consistent with an antimicrobial function for NaThionin; the growth of the bacteria in the presence of the WT protein $(0.25$ and $0.12 \mathrm{mg}$ of total proteins) was significantly lower (48\%) than the growth of the bacteria in samples without any proteins (control) (Fig. 7). Interestingly, the inhibitory effect of NaThionin was not discernible when larger amounts $(0.5 \mathrm{mg})$ of the total protein extract were added to the samples. Larger amounts encouraged $P$. syringae pv. tomato DC3000 to grow vigorously. Compared with the maximum growth rate of bacteria on $0.25 \mathrm{mg}$ of protein from any genotype, $P$. syringae pv. tomato DC3000 growth on $0.5 \mathrm{mg}$ of total protein was at least 6.5 -fold faster. On $1 \mathrm{mg}, P$. syringae pv. tomato DC3000 growth was so rapid as not to be quantifiable under the assay conditions. These results suggest that crude NaThionin, when added to the bacterial growth media, may be stable and effective even in in vitro conditions in a dose-dependent manner and that it may act against pathogens by interacting directly with their membranes.

\section{DISCUSSION}

Two observations motivated us to study the role of PR proteins in plant-pathogen interaction: i) the increase in the transcripts of two $P R$ genes (NaPR-1 and $\mathrm{NaPR} 13 / \mathrm{NaThionin})$ accompanied by the transient increase in SA following $P$. syringae pv. tomato DC3000 inoculation in N. attenuata-such an increase suggests that NaPR-1 and NaPR-13/NaThionin may serve as antibacterial defense proteins under field conditions; and ii) the absence of evidence to support the idea that PR-1 protein is necessary and sufficient for bacterial resistance (van Loon et al. 2006). In comparison with WT and irPR-1 plants, irThionin plants were more susceptible to $P$. syringae pv. tomato DC3000. Clearly the in vitro and in vivo bioassays under laboratory conditions as well as the pathogen performance results under field conditions suggest that only NaThionin, not NaPR-1, acts as an antibacterial protein and is able to restrict opportunistic pathogens.

$P R-1$ is a highly conserved gene family and $\mathrm{Na} P R-1$ has a high homology with $P R-1$ from $N$. tabacum. PR-1 is known to accumulate in the stomatal guard cells, glandular trichomes, crystal idioblasts, and vascular bundles of infected leaves, which is consistent with the view that PR-1 protects vital plant parts involved in metabolite movement and provides protection at points of possible microbial entry into leaves (Hoegen et al. 2002). Yet no evidence supporting PR-1's role as an antimicrobial defense protein was found in our study.

Multiple copies of $P R-1$ are known to exist (van Loon et al. 2006), and the different gene copies are likely to be functionally redundant. As a result, mutating or silencing one copy of $P R-1$ may not be sufficient to affect basal resistance. In $N$. attenuata, we cloned another $P R-1(\mathrm{NaPR}-1 b)$ which has a close homology to the basic PR-1 gene of $N$. tabacum, but $\mathrm{Na} P R-1 b$ in comparison with $\mathrm{Na} P R-1$ is poorly induced, suggesting that NaPR-1 plays a more predominant role than NaPR-1b in resisting $P$. syringae pv. tomato DC3000. Moreover, $\mathrm{Na} P R-1$ and $\mathrm{Na} P R-1 b$ do not share a continuous identical sequence of 23 nucleotides (nt); therefore, it is very likely that the sequence used in the transformation vector to silence $\mathrm{Na} P R-1$ would not co-silence $\mathrm{Na} P R-1 b$, because a minimum of $23 \mathrm{nt}$ of continuous identical sequence is required to silence an endogenous gene (Thomas et al., 2001). Therefore,

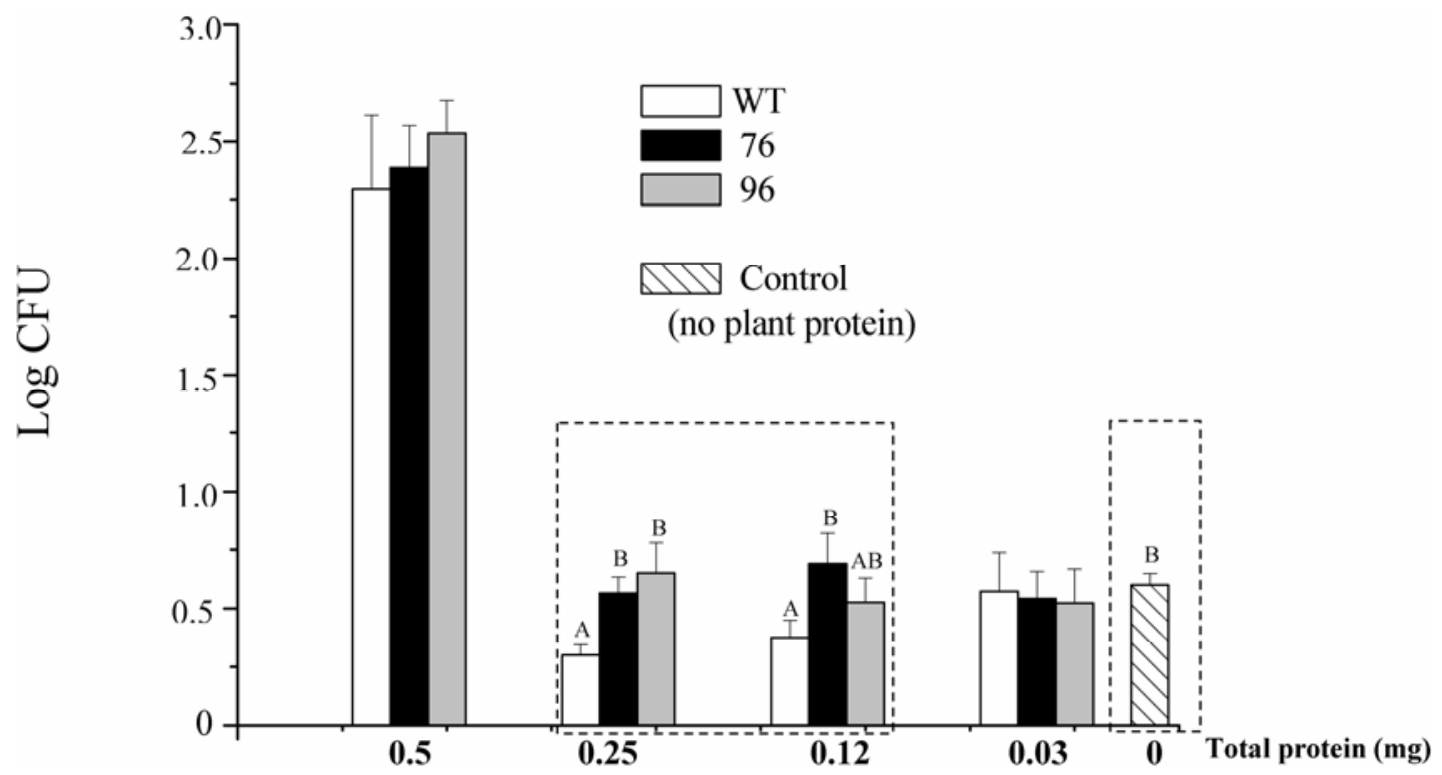

Fig. 7. Total proteins isolated from wild-type (WT) and NaThionin-silenced plants suppress Pseudomonas syringae pv. tomato DC3000 growth in vitro in a Thionin-dependent manner. Different concentrations of total plant protein (volume adjusted to $1 \mathrm{ml}$ using a filter-sterilized extraction buffer) isolated from systemic leaves of $P$. syringae pv. tomato DC3000-infected WT plants and irThionin lines (76 and 94) plants. Known amounts of protein extract were added to $15-\mathrm{ml}$ tubes containing $3 \mathrm{ml}$ of Luria-Bertani (LB) and $10 \mu \mathrm{l}$ of P. syringae pv. tomato DC3000 grown overnight (optical density $=0.6$ ) (control tubes had similar contents, though no plant proteins). Bacteria were allowed to multiply for $14 \mathrm{~h}$ at $28^{\circ} \mathrm{C}$. To quantify bacterial growth, $40 \mu \mathrm{l}$ of $P$. syringae pv. tomato DC3000 grown overnight was plated on LB agar plates. The plates were counted for their CFU after being incubated for 14 h at $28^{\circ} \mathrm{C}$. Values are the mean $( \pm$ standard error) CFU from five biological replicate plants. Different letters indicate significant differences between bacteria grown in the designated treatments compared with those grown in control tubes without plant proteins; $P<0.05$. 
a plausible explanation for why $\mathrm{Na} P R-1$, a highly induced gene, is biologically ineffective against $P$. syringae pv. tomato DC3000 and different isolates of Pseudomonas spp. in the field may be that other defense proteins or other PR proteins (e.g., PR-2 or PR-3) or unidentified isoforms of PR-1 are sufficient to mediate basal resistance and that these other PR proteins might be masking the effect of NaPR-1. Similarly, neither tomato nor tobacco plants engineered to constitutively express different forms of $P R-1$ exhibited increased resistance to PHYTOPHTHORA infestans (van Loon et al. 2006). Therefore, whether $\mathrm{Na} P R-1$ alone effectively functions as a direct defense against microbes remains unknown.

Given that $P R-1$ is a reliable marker of pathogen resistance, it might be playing roles other than as a direct defense, as suggested by the roles played by PR-1 homologues in other organisms. For example, $P R$ - 1 -like homologues in yeast, insects, and vertebrates function as allergens (Edreva 2005) which might benefit the pathogen rather than the plant, if an allergen functions as an antifeedant against herbivores. In this way, the pathogen could reduce the competition for the food source from higher organisms. PR-1-like protein mediates cell division and development in nematodes (Caenorhabditis elegans). LON-1, a protein in C. elegans, regulates the endoreduplication of hypodermal nuclei; as a result of the loss of lon-1, hyper-endoreduplication of hypodermal nuclei was observed (Morita et al. 2002). Endoreduplication is known to occur in pathological conditions such as tumorigenesis, especially in animal model systems (Holland et al. 1998; Lengauer et al. 1998) and, if similar processes occur in plants following pathogen infection, PR-1 could function to regulate endoreduplication. These studies highlight the value of considering functions for PR-1 other than those of a defense protein in pathogen-attacked plants.

We found that NaThionin was effective in resisting $P$. syringae pv. tomato DC3000. Functions of Thionins in plants have been widely studied, and several homologous peptides in different crop species (wheat, barley, oat, and radish) having antimicrobial properties have been reported (Garcia-Olmedo et al. 1998). NaThionin belongs to the $\gamma$-Thionin class, which are 40 to 45 amino acids long, with eight conserved cysteine residues that form four disulfide bridges and contribute to the stability of the protein. These proteins usually occur as gene families, which is also true for NaThionins. The variation in sequence is believed to be the reason for the wide range of antimicrobial activity of Thionins. NaThionin and NaThioninl also show such variation. Apart from minor nucleotide difference in the sequence, three deletions at positions 77 , 83 , and 84 in NaThionin 1 compared with NaThionin emerge as a distinguishing feature of the two cDNAs. These deletions cause a frame shift in the ORF of NaThionin 1 , which is terminated prematurely. The transgene we used in the silencing construct is likely capable of silencing both copies of Thionin due to the presence of 54 shared identical continuous nucleotides, whereas only $23 \mathrm{nt}$ are required to silence an endogenous gene (Thomas et al. 2001). Although it is possible that co-silencing NaThionin and NaThioninl may have rendered plants more susceptible to pathogens, from the low levels of NaThionin 1 transcripts, we infer that NaThionin plays a more dominant role than does NaThionin1.

The results from the in vitro bacterial assay clearly support the view that Thionins are stable peptides with a wide range of antimicrobial activity. At low protein concentrations, only protein extracts from WT plants inhibited P. syringae pv. tomato DC3000 growth; proteins from NaThionin-silenced plants did not. At higher protein concentrations, the inhibitory effect of Thionin is either masked or may even favor higher bacterial growth. Adding proteins to soya bean meal actually made $\mathrm{Fi}$ brobacter succinogenes grow better (May et al. 1993). However, consistent with the dose-dependent bactericidal activity of NaThionin that we observed, cow pea Thionin II (cpThionin II) exhibited dose-dependent bactericidal activity against gram-positive and gram-negative bacteria in cow pea (Vigna unguiculata). The minimum inhibitory concentration of cpThionin II was lowest for P. syringae compared with Escherichia coli and a gram-positive bacteria, Staphylococcus aureus (Franco et al. 2006).

A defensin-like protein highly homologous (>98\%) to NaThionin, $N$. alata Defensin1 (NaD1), has been suggested to play a role apart from its antimicrobial role, namely as an insecticidal protein (Lay et al. 2003). However, in our study, we found no evidence that silencing NaThionin expression increased plants' susceptibility to herbivores that were attacking plants in $N$. attenuata's native habitat. One reason why NaThionin expression is increased after herbivore attack might be to prevent any secondary infection at feeding sites. Clearly, pathogen damage accounted for the high mortality of NaThionin-silenced plants under natural conditions but whether any of these pathogens are vectored by herbivores or otherwise opportunistically infect wounds inflicted by herbivores remains unknown.

Except for a few PR proteins (PR-2, PR-3, and PR-5), the role of PR proteins in mediating basal defense against pathogen remains unknown. The absence of experiments that compare the microbial performance on PR gene-silenced or mutated plants with that of WT plants under both laboratory and field conditions has hampered our understanding of the function of PR proteins. Furthermore, the diversity and the occurrence of PR genes in many organisms suggest that PR proteins can carry out functions which are not directly related to pathogen defense. Therefore, it would not be surprising to find that PR proteins not only function as direct defense proteins but are also involved in processes other than defense.

\section{MATERIALS AND METHODS}

Plant material, $P$. syringae growth, and plant treatments.

WT $N$. attenuata plants were inbred for 14 generations (seed were collected from a native population from the DI Ranch, Santa Clara, UT, U.S.A.). IrPR- 1 lines (172 and 217) and irThionin lines (76 and 96) were produced in the same WT genetic background. Germination was carried out according to the procedures described by Krügel and associates (2002). Growth-chamber (photoperiod of 16 and $8 \mathrm{~h}$ at 25 and $21^{\circ} \mathrm{C}$, respectively, and 45 to $55 \%$ relative humidity) experiments were carried out with rosette-stage plants 13 days after they were transferred to 1-liter pots.

$P$. syringae pv. tomato strain DC3000 was grown on LuriaBertani (LB) agar plates at $28^{\circ} \mathrm{C}$. The $P$. syringae pv. tomato DC3000 growth and inoculation procedure was carried out as described by Krzymowska and associates (2007) with the following modification: a stock solution containing $1 \times 10^{5}$ cells $/ \mathrm{ml}$ instead of the originally described $1 \times 10^{8}$ cells $/ \mathrm{ml}$ was used. Five to six spots per nodal leaf of WT, NaPR-1-, and NaThionin-silenced plants were inoculated with $100 \mu \mathrm{l}$ of $P$. syringae pv. tomato DC3000 or water (control). For the leaf dip assay, $1 \times 10^{8}$ cells $/ \mathrm{ml}$ were resuspended in $0.05 \%$ Silwett L-77 solution as described by Katagiri and associates (2002) and intact leaves were dipped for $30 \mathrm{~s}$. As a control, leaves were dipped in $0.05 \%$ Silwett L-77 solution.

$\mathrm{W}+\mathrm{OS}$ treatment was done by wounding plant leaves at node +1 with a pattern wheel and, immediately, $20 \mu \mathrm{l}$ of onefifth diluted (vol/vol in water) $M$. sexta oral secretions were applied to the wounds. 
Isolating NaPR-1, NaPR-1b, NaThionin, and NaThionin1; generating and characterizing $\mathrm{Na} P R-1-$ and

NaThionin-silenced plants.

Using the sequence information of $N$. tabacum $P R-1 a$ (X12485.1, NCBI) (Cutt et al. 1988), primers were designed (PR1-FP: 5'-ATGTTGTATCTTCACAATTGCCT-3' and PR1RP: 5'-TTAGTATGGACTTTCGCCTC-3') to isolate a 504-bp $N$. attenuata $\mathrm{NaPR}-1$ ORF (sequence submitted to the NCBI database) from the cDNA prepared from SA-treated $N$. attenuata leaves. The SA treatment was carried out as described by Rayapuram and Baldwin (2007). Using primers NaPR1b-1: 5'GGGATACTCCACAACATTAG-3' and NaPR1b-2: 5'GACA TCAGTTGGAAGTTCCA-3', a 536-bp N. attenuata NaPR-1b sequence was isolated from cDNA prepared from $\mathrm{W}+\mathrm{OS}$ treated $N$. attenuata leaves. Previously, NaThionin was identified as a differentially regulated gene in WT $N$. attenuata plants that had been damaged by the specialist herbivore $M$. sexta (accession number AY456268) (Lou and Baldwin 2004). In this study, using primers FLTIO-FP: 5'-ATGGCTCGAT CCTTGTGCTTCATG-3' and FLTIO-RP: 5'-TTAGTTATCCA TCATCTCTTC-3', two Thionin sequences (referred to as NaThionin and NaThionin1) were PCR amplified from the cDNA obtained from $P$. syringae pv. tomato DC3000-inoculated WT leaves. The gene fragments amplified using the above-mentioned primers were excised from the gel, purified using a GFX gel purification kit (GE Healthcare, Little Chalfont, U.K.), and cloned into a pGEM-T Easy vector (Promega, Madison, WI, U.S.A.) following the manufacturer's instructions. The fragments, which were sequenced and compared with the known sequences from the NCBI database, confirmed the sequences as $P R-1$ and Thionin.

To generate transgenic plants, a 363-bp fragment from the $\mathrm{NaPR}-1$ ORF and a 225-bp fragment from the NaThionin ORF were inserted into a pRESC5 transformation vector to create inverted-repeat constructs. These constructs were transformed into N. attenuata WT plants using an Agrobacterium-mediated transformation procedure described by Krügel and associates (2002). The gene for hygromycin resistance (hptII) allowed transformed plants to be identified by selecting hygromycinresistant individuals (Krügel et al. 2002).

\section{Nucleic acid analysis.}

Southern blot analysis. DNA was extracted from the leaf tissue of fully developed plants using the cetyltrimethylammonium bromide (CTAB) method as described by Doyle and Doyle (1987). For the Southern blot hybridizations, $10 \mu \mathrm{g}$ of the DNA samples was digested with different restriction enzymes at $37^{\circ} \mathrm{C}$ overnight, separated on a $0.8 \%$ (wt/vol) agarose gel, and Southern blotted onto a nylon membrane. The NaThionin probe (FLTIO-FP: 5'-ATGGCTCGATCCTTGTGC TTCATG-3' and FLTIO-RP: 5'-TTAGTTATCCATCATCTCTT C-3') and an hptII probe (forward primer: 5'-CGTCTGTCGA GAAGTTTCTG-3' and reverse primer: $3^{\prime}$-CCGGATCGGACG ATTGCG-5') generated by PCR amplification were used for Southern hybridization to confirm the copy number and single insertion transgenic lines, respectively. Both probes were labeled with $\alpha-32 \mathrm{P}$ (Rediprime II DNA-labeling system, GE Healthcare).

Transcript analysis. To analyze NaPR-1 and NaThionin transcripts, we extracted total RNA with TRIzol reagent (Invitrogen, San Diego, CA, U.S.A.) following the TIGR protocol. cDNA was synthesized from $1 \mu \mathrm{g}$ of RNA using the SuperScript II RT enzyme (Invitrogen). Quantitative real-time PCR (ABI PRISM 7000; Applied Biosystems, Foster City, CA, U.S.A.) was conducted using the qPCR core reagent kit (Eurogentec, Seraing, Belgium). To analyze $\mathrm{Na} P R-1$, a specific TaqMan primer pair (forward primer: 5'-ACGCTTGTCATGC
CCAG-3' and reverse primer: 5'-CAGGTTAAAGGTTCTACG CCT-3') and a double-fluorescent dye-labeled probe (5'-GGG ATGCCCATACACAGCTCGTG-3') were used. To analyze NaThionin, a specific TaqMan primer pair (forward primer: 5' AACTATGGCTCGCTCCTTGTGC-3' and reverse primer: 5' $^{\prime}$ CTCATAGGCAACAAAAAGCAT-3') and a double-fluorescent dye-labeled probe (5'-TTCATGGCATTTGCAGTCTTGG CAA- $3^{\prime}$ ) were used. The relative gene expression was calculated using a 10-fold dilution series of cDNAs which had been transcribed from induced RNA samples from the same experiment.

\section{RT-PCR analysis.}

RT-PCR was carried out with $100 \mathrm{ng}$ of cDNA prepared from leaf tissues that were challenged with $P$. syringae pv. tomato DC3000 for $48 \mathrm{~h}$. As an endogenous and loading control, we used ECI (Rayapuram and Baldwin 2006) as a reference gene. PCR reaction was carried out for 23 cycles.

\section{In vitro bioassay of the effect of proteins isolated from WT and NaThionin-silenced plants on $P$. syringae pv. tomato $\mathrm{DC} 3000$ growth.}

Using $1 \mathrm{ml}$ of filter-sterilized $1 \mathrm{mM}$ Tris- $\mathrm{HCl}$ buffer $(\mathrm{pH}$ 7.5) per gram of finely ground systemic leaf tissue of WT plants and irThionin lines (76 and 94) infected with P. syringae pv. tomato DC3000, total plant proteins were isolated by onestep centrifugation at $15,000 \times g$. Extractions were carried out under sterile conditions. Different concentrations of total plant protein (volume adjusted to $1 \mathrm{ml}$ using a filter-sterilized extraction buffer) were added to $15-\mathrm{ml}$ tubes containing $3 \mathrm{ml}$ of LB and $10 \mu \mathrm{l}$ of $P$. syringae pv. tomato DC3000 grown overnight (optical density $=0.6$ ) (control tubes the same constituents, though no plant proteins). Total plant proteins $(1 \mathrm{mg}) \mathrm{re}-$ sulted in higher and robust bacterial growth and, hence, concentrations less than $1 \mathrm{mg}$ were used in the assay. Bacteria were allowed to multiply for $14 \mathrm{~h}$ at $28^{\circ} \mathrm{C}$. To quantify bacterial growth, $40 \mu \mathrm{l}$ of $P$. syringae pv. tomato DC3000 grown overnight was plated on LB agar plates. The plates were counted for their CFU after being incubated for $14 \mathrm{~h}$ at $28^{\circ} \mathrm{C}$.

\section{Analysis of phytohormones (SA and JA).}

For phytohormone analysis, leaf samples from five replicate plants were used. Approximately $300 \mathrm{mg}$ of each tissue sample was extracted in Fast-Prep tubes containing $0.9 \mathrm{~g}$ of Fast-Prep matrix, flash-frozen in liquid nitrogen, and stored at $-80^{\circ} \mathrm{C}$ until use. The extraction procedure and the analysis of phytohormones were as described in Rayapuram and Baldwin (2007).

\section{Insect and pathogen performance under field conditions.}

WT and transgenic lines irPR-1 lines (172) and irThionin lines (96) were planted in the natural habitat of $N$. attenuata at the Lytle Ranch Preserve near Santa Clara, UT, U.S.A. Seed of WT and transgenic plants were germinated on agar plates. The plates were incubated at $25^{\circ} \mathrm{C}$ for $16 \mathrm{~h}$ of light $\left(200 \mu \mathrm{m} / \mathrm{s} / \mathrm{m}^{2}\right)$ and $20^{\circ} \mathrm{C}$ for $8 \mathrm{~h}$ of darkness. After 10 days, seedlings were transferred to Jiffy 703 pots $(13 / 4$ by $13 / 4$ in.; AlwaysGrows, Sandusky, OH, U.S.A.) which had been soaked in borax solution ( $0.4 \mathrm{mg}$ per $45 \mathrm{ml}$ of water). The seedlings were fertilized with iron solution (stock solution: $2.78 \mathrm{~g}$ of $\mathrm{FeSO}_{4} \cdot 7 \mathrm{H}_{2} \mathrm{O}$ and $3.93 \mathrm{~g}$ of Titriplex in 1 liter of $\mathrm{H}_{2} \mathrm{O}$, diluted 100-fold for fertilization) after 7 days. Seedlings were allowed to gradually adapt to the environmental conditions of the Great Basin Desert (high sun exposure and low relative humidity) over 2 weeks in a mesh tent before being transplanted to the field sites. Plants were transplanted in size-matched pairs to an irrigated field plantation at the Lytle Ranch Preserve and into native $N$. attenuata populations in a 
blackbrush and pinyon-juniper forest that had burned in 2005. Seventeen transgenic WT pairs of size-matched acclimated seedlings were planted in transects at the burn site. Seedlings were watered every other day for 2 weeks until roots were established in the native soil. The release of transgenic plants was carried out under APHIS notification (06003-08n). To comply with 7CFR 340.4, the legal statute which governs the release of transgenic organisms, plants were either harvested and destroyed before the start of flowering (burn site) or flowers were removed before seed matured (plantation site).

We analyzed the total herbivore and pathogen damage 23 , 25 , and 27 days after transplanting to the field sites. We estimated the percentage of leaf area removed (in the case of grasshoppers) or the percentage of characteristic damage caused by specific herbivores or pathogens relative to the total leaf area as described by Paschold and associates (2007). Damage was expressed as the percentage of canopy damage per plant or the total percentage of damage divided by the total number of leaves.

\section{Pathogen identification.}

We collected leaves infected by naturally occurring pathogens from the field and cultured them on LB media. Single colonies distinct from other colonies in color and morphology were picked and replated. Five isolates were purified from the infected leaves. Plates containing single colonies were sent to Amodia (Braunschweig, Germany) for identification. A single colony from five different plates was sequenced for the $16 \mathrm{~S}$ ribosomal RNA to identify the pathogen. Three isolates had 16S sequences with more than $98 \%$ similarity to those of Pseudomonas spp. and two other isolates matched the isolate of Pantoea spp.

\section{Oligonucleotide microarray analysis.}

A customized microarray containing 50-mer oligonucleotides representing 1,404 genes was designed by spotting each oligo four times onto epoxy-coated glass slides (Quantifoil Microtools, Jena, Germany) (Voelckel and Baldwin 2004a,b). RNA was extracted from irThionin lines (76 and 96) and WT plants that had been inoculated with $P$. syringae pv. tomato DC3000 for $24 \mathrm{~h}$. cDNA from $P$. syringae pv. tomato DC3000-inoculated leaves of irThionin lines (76 and 96) was Cy3 labeled and cDNA from the $P$. syringae pv. tomato DC3000-inoculated leaves of WT plants was Cy5 labeled. A competitive hybridization was performed on the gene-spotted epoxy slides. Each hybridization was replicated three times. An Affymetrix 428TM array scanner (High Wycombe, U.K.) was used to scan the microarrays sequentially for Cy3-and Cy5-labeled cDNA at a maximum resolution of $10 \mu \mathrm{m} /$ pixel with a 16-bit depth. The final data were statistically analyzed using a Lowess-normalization procedure with the MIDAS package (TIGR microarray data analysis system). For a gene to qualify as up- or downregulated, a minimum of a 1.5-fold change in expression ratio was required as well as a $t$ test at confidence level $(\alpha) 0.05$ for the quadruplicate spots of each gene. A gene was regarded as differentially regulated if it met both criteria in both microarrays from each line. In some cases, a gene was also defined to be significantly regulated when the signal of the gene was present in only one channel and the density was more than 2.5-fold the signal-to-noise ratio.

\section{Statistical analysis.}

Data were analyzed with StatView (Abacus Concepts, Inc., Berkeley, CA, U.S.A.). One-way ANOVAs with Bonferronicorrected post-hoc tests were used to analyze the data.

\section{ACKNOWLEDGMENTS}

We thank K. Gase, T. Hahn, S. Kutschbach, S. Allmann, A. Wissgott, E. Rothe, C. Hettenhausen, and W. Kroeber for assistance in preparing, cloning, sequencing, microarray analysis, and bacterial inoculations, N. Qu, D. Kessler, and R. Halitschke for assistance in the field, E. Wheeler for editorial assistance, the Max Planck Society for funding, and Brigham Young University for the use of the field station, Lytle Preserve.

\section{LITERATURE CITED}

Asai, T., Tena, G., Plotnikova, J., Willmann, M. R., Chiu, W. L., GomezGomez, L., Boller, T., Ausubel, F. M., and Sheen, J. 2002. MAP kinase signalling cascade in Arabidopsis innate immunity. Nature 415:977983.

Bachmann, D. E., Rezzonico, D., Retelska, A., Chételat, S., and Beffa, S. R. 1998. Improvement of potato resistance to Phytophthora infestans by overexpressing antifungal hydrolases. Abstract. Page 57 in: 5th International Workshop on Pathogenesis-Related Proteins. Signalling Pathways and Biological Activities. Aussois, France.

Bent, A. F., Innes, R. W., Ecker, J. R., and Staskawicz, B. J. 1992. Disease development in ethylene insensitive Arabidopsis thaliana infected with virulent and avirulent Pseudomonas and Xanthomonas pathogens. Mol. Plant-Microbe Interact. 5:372-378.

Carmona, M. J., Molina, A., Fernandez, J. A., Lopez-Fando, J. J., and Garcia-Olmedo, F. 1993. Expression of the alpha-Thionin gene from barley in tobacco confers enhanced resistance to bacterial pathogens. Plant J. 3:457-462.

Chandrashekar, A., and Satyanarayana, K.V. 2006. Disease and pest resistance in sorghum and millet grains. J. Cereal Sci. 44:287-304.

Cutt, J. R., Dixon, D. C., Carr, J. P., and Klessig, D. F. 1988. Isolation and nucleotide sequence of cDNA clones for the pathogenesis-related proteins PR1a, PR1b and PR1c of Nicotiana tabacum cv. Xanthi nc induced by TMV infection. Nucleic Acids Res. 16:9861.

Doyle, J. J., and Doyle, J. L. 1987. A rapid DNA isolation procedure for small quantities of fresh leaf tissue. Phytochem. Bull. 19:11-15.

Edreva, A. 2005. Pathogenesis-related proteins: Research progress in the last 15 years. Gen. Appl. Plant Physiol. 31:105-124.

Fagoaga, C., Rodrigo, I., Conejero, V., Hinarejos, C., and Tuset, J. J. 2001. Increased tolerance to Phytophthora citrophthora in transgenic orange plants constitutively expressing a tomato pathogenesis related protein PR-5. Mol. Breed. 7:175-185.

Florack, D. E. A., Visser, B., De Vries, Ph. M., Van Vuurde, J. W. L., and Stiekema, W. J. 1993. Analysis of the toxicity of puroThionins and hordoThionins for plant-pathogenic bacteria. Neth. J. Plant Pathol. 99:259268.

Franco, O. L., Murad, A. M., Leite, J. R., Mendes, P., Prates, M. V., and Bloch, C. 2006. Identification of a cowpea $\gamma$-Thionin with bactericidal activity. FEBS (Fed. Eur. Biochem. Soc.) J. 273:3489-3497.

Garcia-Olmedo, F., Molina, A., Alamillo, J. M., Rodríguez-Palenzuéla P. 1998. Plant defense peptides. Biopolymers 47:479-491.

Gomez-Gomez, L., and Boller, T. 2002. Flagellin perception: A paradigm for innate immunity. Trends Plant Sci. 7:251-256.

Halitschke, R., and Baldwin, I. T. 2003. Antisense LOX expression increases herbivore performance by decreasing defense responses and inhibiting growth-related transcriptional reorganization in Nicotiana attenuata. Plant J. 36:794-807.

Hoegen, E., Stromberg, A., Pihlgren, U., and Kombrink, E. 2002. Primary structure and tissue-specific expression of the pathogenesis-related protein PR-1b in potato. Mol. Plant Pathol. 3:329-345.

Hofius, D., Tsitsigiannis, D. I., Jones, J. D. G., and Mundy, J. 2007. Inducible cell death in plant immunity. Semin. Cancer Biol. 17:166-187.

Holland, E. C., Hively, W. P., DePinho, R. A, and Varmus H. E. 1998. A constitutively active epidermal growth factor receptor cooperates with disruption of G1 cell-cycle arrest pathways to induce glioma-like lesions in mice. Genes Dev. 12:3675-3685.

Iwai, T., Kaku, H., Honkura, R., Nakamura, S., Ochiai, H., Sasaki, T., and Ohashi, Y. 2002. Enhanced resistance to seed-transmitted bacterial diseases in transgenic rice plants overproducing an oat cell-wall-bound Thionin. Mol. Plant-Microbe Interact. 15:515-521.

Jonak, C., Okresz, L., Bogre, L., and Hirt, H. 2002. Complexity, cross talk and integration of plant MAP kinase signalling. Curr. Opin. Plant Biol. 5:415-424.

Katagiri, F., Thilmony, R., and He, S. Y. 2002. The Arabidopsis thalianaPseudomonas syringae interaction. In: The Arabidopsis Book. C. R. Somerville and E. M. Meyerowitz, eds. American Society of Plant Biologists, Rockville, MD, U.S.A. doi:10.1199/tab.0009. Published online.

Krügel, T., Lim, M., Gase, K., Halitschke, R., and Baldwin, I. T. 2002. 
Agrobacterium-mediated transformation of Nicotiana attenuata, a model ecological expression system. Chemoecology 12:177-183.

Krzymowska, M., Konopka-Postupolska, D., Sobczak, M., Macioszek, V, Ellis B. E., and Hennig, J. 2007. Infection of tobacco with different Pseudomonas syringae pathovars leads to distinct morphotypes of programmed cell death. Plant J. 50:253-264.

Lay, F. T., Schirra H. J., Scanlon M. J., Anderson M. A., and Craik, D. J. 2003. The three- dimensional solution structure of NaD1, a new floral defensin from Nicotiana alata and its application to a homology model of the crop defense protein alfAFP. J. Mol. Biol. 325:175-188.

Lengauer, C., Kinzler, K. W., and Vogelstein, B. 1998. Genetic instabilities in human cancers. Nature 396:643-649.

Lou, Y., and Baldwin. I. T. 2004. Nitrogen supply influences herbivore-induced direct and indirect defenses and transcriptional responses in Nicotiana attenuata. Plant Physiol. 135:496-506.

May, T., Kerley, M. S., and Williams, J. E. 1993. Supplemental protein influences on carbohydrate degradation and bacterial 16s ribosomal ribonucleic acid. J. Dairy Sci. 76:3479-3489

Morita, K., Flemming A. J., Sugihara, Y., Mochii, M., Suzuki, Y., Yoshida, S., Wood, W. B., Kohara, Y., Leroi, A. M., and Ueno, N. 2002. A Caenorhabditis elegans TGF-beta, DBL-1, controls the expression of LON-1, a PR-related protein, that regulates polyploidization and body length. EMBO (Eur. Morl. Biol. Organ.) J. 21:1063-1073.

Mysore, K. S., and Ryu, C. M. 2004. Nonhost resistance: How much do we know? Trends Plant Sci. 9:97-104.

Niki, T., Mitsuhara, I., Seo, S., Ohtsubo, N., and Ohashi, Y. 1998. Antagonistic effect of salicylic acid and jasmonic acid on the expression of pathogenesis related (PR) protein genes in wounded mature tobacco leaves. Plant Cell Physiol. 39:500-507.

Nurnberger, T., and Lipka, V. 2005. Non-host resistance in plants: New insights into an old phenomenon. Mol. Plant Pathol. 6:335-345.

Paschold, A., Halitschke, R., and Baldwin, I. T. 2007. NaCOI1 mediates herbivore- induced resistance in Nicotiana attenuata and reveals the role of herbivore movement in avoiding defenses. Plant J. 51:79-91.

Rayapuram, C., and Baldwin, I. T. 2006. Using nutritional indices to study LOX3-dependent insect resistance. Plant Cell Environ. 29:1585-1594.

Rayapuram, C, and Baldwin, I. T. 2007. Increased SA in NPR1-silenced plants antagonizes JA and JA-dependent direct and indirect defenses in herbivore-attacked Nicotiana attenuata in nature. Plant J. 52:700-715.

Stec, B. 2006. Plant Thionins-the structural perspective. Cell. Mol. Life Sci. 63:1370-1385

Thomas, C. L., Jones, L., Baulcombe, D. C., and Maule, A. J. 2001. Size constraints for targeting post-transcriptional gene silencing and for RNA-directed methylation in Nicotiana benthamiana using a Potato virus $X$ vector. Plant J. 25:1-11.

van Loon, L. C., Rep, M., and Pieterse, C. M. J. 2006. Significance of inducible defense- related proteins in infected plants. Annu. Rev. Phytopathol. 44:135-162.

Vernooij, B., Friedrich, L., Morse, A., Reist, R., Kolditz-Jawhar, R., Ward, E., Uknes, S., Kessmann, H., and Ryals, J. 1994. Salicylic acid is not the translocated signal responsible for inducing systemic acquired resistance but is required in signal transduction. Plant Cell 6:959-965.

Voelckel, C., and Baldwin, I. T. 2003. Detecting herbivore-specific transcriptional responses in plants with multiple DDRT-PCR and subtractive library procedures. Physiol. Plant. 118:240-252.

Voelckel, C., and Baldwin, I. T. 2004a Generalist and specialist lepidopteran larvae elicit different transcriptional responses in Nicotiana attenuata, which correlate with larval FAC profiles. Ecol. Lett. 7:770775 .

Voelckel, C., and Baldwin, I. T. 2004b. Herbivore-induced plant vaccination. Part II. Array-studies reveal the transience of herbivore-specific transcriptional imprints and a distinct imprint from stress combinations. Plant J. 38:650-663.

Ward, E. R., Uknes, S. J., Williams, S. C., Dincher, S. S., Wiederhold, D. L., Alexander, D. C., Ahlgoy, P., Metraux, J. P., and Ryals, J. A. 1991. Coordinate gene activity in response to agents that induce systemic acquired-resistance. Plant Cell 3:1085-1094.

Zhang, S., and Klessig, D. F. 2001. MAPK cascades in plant defense signaling. Trends Plant Sci. 6:520-527.

\section{AUTHOR-RECOMMENDED INTERNET RESOURCES}

The Institute for Genomic Research (TIGR) microarray data analysis: www.tm4.org/

TIGR website: www.tigr.org 